\title{
Living the Categorical Imperative: autistic perspectives on lying and truth telling-between Kant and care ethics
}

Pier Jaarsma, Petra Gelhaus and Stellan Welin

\section{Linköping University Post Print}

N.B.: When citing this work, cite the original article.

The original publication is available at www.springerlink.com:

Pier Jaarsma, Petra Gelhaus and Stellan Welin, Living the Categorical Imperative: autistic perspectives on lying and truth telling-between Kant and care ethics, 2011, Medicine, Health care and Philosophy, (15), 3, 271-277.

http://dx.doi.org/10.1007/s11019-011-9363-7

Copyright: Springer Verlag (Germany) http://www.springerlink.com/?MUD=MP

Postprint available at: Linköping University Electronic Press http://urn.kb.se/resolve?urn=urn:nbn:se:liu:diva-72173 
Lying is a common phenomenon amongst human beings. It seems to play a role in making social interactions run more smoothly. Too much honesty can be regarded as impolite or downright rude. Remarkably, lying is not a common phenomenon amongst normally intelligent human beings who are on the autism spectrum. They appear to be attractively morally innocent' and seem to have an above average moral conscientious objection against deception. In this paper, the behavior of persons with autism with regard to deception and truthfulness will be discussed in the light of two different ethical theories, illustrated by fragments from autobiographies of persons with autism. A systemizing 'Kantian' and an empathizing 'ethics of care' perspective reveal insights on high-functioning autism, truthfulness and moral behavior. Both perspectives are problematic from the point of view of a moral agent with autism. High-functioning persons with autism are, generally speaking, strong systemizers and weak empathizers. Particularly, they lack 'cognitive empathy' which would allow them to understand the position of the other person. Instead, some tend to invent a set of rules that makes their behavior compatible with the expectations of others. From a Kantian point of view, the autistic tendency to always tell the truth appears praiseworthy and should not be changed, though it creates problems in the social life of persons with autism. From a care ethics perspective, on the other hand, a way should be found to allow the high-functioning persons with autism to respect the feelings and needs of other persons as sometimes overruling the duty of truthfulness. We suggest this may even entail 'morally educating' children and adolescents with autism to become socially skilled empathic 'liars'. 


\section{Introduction}

This article moves between the fields of reported self-experience of persons who are on the Autism spectrum, moral psychology and moral philosophy. We will use insights and ideas from Kantian discussions as well as from Ethics of care. It is clearly not the intention to contribute to a deep exegesis of Immanuel Kant's works, neither to enter the Neokantian debate. Neither is our aim to bring forward the highly interesting developments in care ethics, or the combinations of both in terms of relational autonomy and moral community. We intend to analyze critically some observations that are made from a moral psychological background on behalf of persons who are on the Autism spectrum. We hope to show by this example how crucial a mutual inspiration and information between the empirical and the conceptual side is for insights in ethics and moral education.

In most societies, human beings learn that it is not a good thing to lie and cheat or to engage in other deceptive behaviors. It is encountered with disapproval if they show signs of having become too good at that. As it is generally considered a good thing to develop a person's social and moral capabilities, the development of these 'Machiavellian' capabilities (Gavrilets 2006) appears undesirable. Paradoxically, the capacity for deception is most valuable and useful in a society where honesty and non-deception is the rule. If everybody was lying, lying - as well as truth telling - would be pointless.

Lying is not a common phenomenon amongst persons who are on the Autism Spectrum. They are less interested in deception (Baron-Cohen 2008, p. 72). Yet, everyday lies 
are considered to be of the utmost importance to live a healthy ${ }^{1}$ life in relationship with others (Nyberg 1993, p. 2). Therefore we will focus in this paper on the question:

\section{Is it morally good to teach children and adolescents with Autism the social skill of lying?}

Two rather different ethical starting points: a rational Kantian and an empathic 'ethics of care' perspective lead to opposing answers to our question. In this paper we will try to give reasons for preferring one ethical approach over the other.

Firstly, we will briefly explain what Autism is. Secondly, we will summarize psychological explanations for the autistic 'inability' to lie or the autistic tendency to be truthful. Thirdly, we will describe some experiences of lying and being honest written down in autobiographies of persons with Autism. Fourthly, we will discuss the alleged lack of empathy of persons with Autism and its relationship to their (dis)ability to lie. Fifthly, we will talk about a Kantian perspective on lying and being truthful and we will compare it with the autistic 'inability' to lie. Sixthly, an ethics of care perspective on lying and being truthful will be discussed in relation to moral agents with Autism. Finally, we will end with some concluding remarks and present the answer to our question.

\section{What is Autism?}

Whenever we speak of persons with Autism in this paper, we mean high-functioning persons with Autism. These are non-intellectually disabled persons on the Autism spectrum. It is by no means our intention to exclude intellectually disabled persons with Autism from these

\footnotetext{
${ }^{1}$ We understand 'health' holistically, as the ability to reach vital goals under reasonable circumstances (Nordenfelt, 1987).
} 
matters and to disregard their interests. However, in order not to make things needlessly complicated we limit ourselves to high-functioning persons with Autism.

The primary diagnostic abnormalities in Autism spectrum disorder are: qualitative impairment in social interaction, qualitative impairments in communication, and restricted repetitive and stereotyped patterns of behavior, interests, and activities ${ }^{2}$. Sensory difficulties are also quite common (Lawson 2009). Autism spectrum disorder has Asperger's disorder at the mild end, and severe autistic disorder at the other end (Wing 1997). Asperger's Syndrome differs from 'classic' Autism in that those diagnosed with Asperger's do not show evidence of intellectual deficiency or language delay.

\section{Psychological explanations for the autistic 'inability' to lie or the autistic tendency to be} truthful

\footnotetext{
"Chimpanzees are known to be able to engage in deception, which is one of the many points in which they resemble modern humans. Individuals who have an Autistic Spectrum Disorder, on the other hand, tend to be much more honest than "normal" humans; it is very difficult for us to deceive, lie or cheat, and some never learn this "social skill."
}

Jen Birch, (2003) Congratulations! It’s Asperger Syndrome.

Lying is a common phenomenon amongst human beings, yet not amongst persons with Autism, as Jen Birch so eloquently pointed out in her autobiography. A philosophical definition of lying is saying something you believe to be false with the intent to deceive about

\footnotetext{
${ }^{2}$ See DSM- IV-TR.
} 
what you say (Fallis 2010, p.19). In psychological literature lying is viewed as an everyday social interaction process and even as a social skill (DePaulo 1996). People often tell everyday lies for emotional or psychological reasons: to try to make themselves look better or feel better, to protect themselves from embarrassment or disapproval or from having their feelings hurt, and to try to gain the esteem and affection of other people, or simply for the sake of convenience.

It has been acknowledged that cheating is not part of the autistic personality. Jeanette Kennett has called this 'a kind of attractive moral innocence' (Kennett 2002, p. 349). In neurotypical early childhood, the capability of lying and deceiving is formed. The instrument needed for this is called 'cognitive empathy', which is mental perspective taking or 'mentalizing' (Smith 2006, p.3).

Simon Baron-Cohen, an influential psychologist specialized in Autism, claims that children with Autism, in comparison with normal children, seem less able to deceive, because they are unaware of the fact that other people's beliefs can be different from theirs (Baron-Cohen 1999, p. 181). They lack the ability to empathize with others, to understand intentions, emotions and beliefs of other persons. In a sense, they are unable to form 'theory' about other persons' minds. They have a 'Theory of Mind'3 deficit according to Baron-Cohen. The development of 'Theory of Mind' in persons with Autism is a matter of gradation. Autism exists on a continuum: less severely affected have more intact theory-of-mind skills. High-functioning adults with Autism may be able to pass first-order 'Theory of Mind' tasks (like the Sally-Anne test), but still they perform significantly worse than nonautistic participants in advanced Theory of Mind tasks (Kleinman 2001). The consequence of the

\footnotetext{
${ }^{3}$ Although there has been controversy over whether the 'Theory of Mind' thesis is the best psychological explanation for Autism (rival theories are 'Executive Function' thesis and 'Central Coherence' thesis (Barnbaum 2008)), 'Theory of Mind' is to date the most influential psychological explanation of Autism.
} 
'Theory of Mind' deficit is that higher functioning persons with Autism may be able to form interpersonal relationships but only on their own terms (Barnbaum 2007, p. 26).

Baron-Cohen explains the 'inability' to lie of persons with Autism by their strong inclination to 'systemize'. The function of systemizing is to predict laws or patterns in information. Baron-Cohen contends that the autistic brain is 'the ultimate pattern detector and truth detector'. Baron-Cohen refers to persons with Autism as hypersystemizers. They prefer systems that change in highly lawful or predictable ways (Baron-Cohen 2008). Lying is perceived as an infringement of the accepted pattern of reality.

Baron-Cohen praises the autistic brain in a sense by calling it 'scientific'4 However, this is not really true. Persons with Autism are indeed very interested in truth about facts, in detailed particular facts. They seem to perceive details which neurotypicals overlook. ${ }^{5}$ The pattern shaping activity from detailed facts is indeed strikingly similar to the inductive program launched by the philosopher Francis Bacon in the $17^{\text {th }}$ century. This Baconian program has not been very successful. Early scientific development took off by disregarding many particular facts and concentrating on a few. This can be seen clearly in the development of the new physics in the $17^{\text {th }}$ century. The historian of science Thomas Kuhn has characterized this difference as a 'Baconian' and a 'Newtonian' program after its foremost proponents (Kuhn 1977, p. 41ff). It seems that Baron-Cohen overlooks this difference between pattern seeking and thereby casts the autistic brain as more 'scientific' than is warranted.

Lying and truth telling is not only about whether or not facts are being stated; it is also about performing actions, to bring about certain wanted states of affairs or to prevent

\footnotetext{
4 "In a high-functioning individual on the autistic spectrum, such pattern seeking can reveal scientific truths about the nature of reality, since their systemizing can help the individual understand how things work." (BaronCohen 2008, p. 69) [Emphasis added]

${ }^{5}$ This is due to 'weak central coherence' (Kenneth 2002; Barnbaum 2008). 'Central coherence' is the ability to see not merely parts, but wholes - the ability to draw together details so as to recognize the meaning of the entire picture (Barnbaum 2008, p. 27, 28). Persons with Autism tend to focus on details and seem to have limited understanding of the whole.
} 
certain unwanted states of affairs of taking place. The goal of a healthy livable human lifetime of relationships with others is undeniably a wanted state of affairs by the utmost majority of humankind. Persons with Autism are not an exception to this. According to the philosopher David Nyberg (1993 p. 2) this goal is inconceivable without deception. Viewed from such a perspective, the truthfulness of persons with Autism is an obstacle towards that end, as becomes clear from autobiographical reports of persons with Autism.

\section{Experiences of lying and being honest described in autobiographies of persons with}

\section{Autism}

By way of illustration some experiences of lying and being honest described in autobiographies of persons with Autism $^{6}$ will now be given. Temple Grandin, an autobiographer with Autism, writes: "Even though honesty is the best policy, my opinion about other people's appearance was usually not welcome [...]. Through many specific examples, I developed a category of "rude honesty" when I needed to keep my mouth shut $[\ldots] . "$

Caiseal Mor, another autobiographer with Autism, writes: “Then I began saying things that offended people. I said what was on my mind. I didn't hold back. I was impolite. I was brutally honest. I was rude.”

It seems that these autobiographers with Autism learned it 'the hard way' that being honest is not always appreciated in human relationships. Had they been neurotypical,

\footnotetext{
${ }^{6}$ It is not our intention to generalize and hypothesize from a sampling of autobiographies of persons with Autism. The problem with autobiographies in general is that people usually want to paint a good picture of themselves. An additional problem with autobiographies of persons with Autism is the uncertainty over the quantity and quality of editing a manuscript has undergone. Nevertheless and having these reservations in mind, there is no better way to get insight into the inner world of another person than his or her self-reports.
} 
this insight would probably have come to them more 'naturally' and much sooner.

Whether persons with Autism are able to tell a lie or to deceive somebody at all, can easily be answered by looking at some text fragments of autobiographies of persons with Autism: 'I promptly told a white lie' (Fleisher 2003, p. 102); 'I become extremely anxious when I have to tell a little white lie [...]' (Grandin 2006, p.156); 'As a child, I had told many lies as a survival tactic [...]' (Schneider 1999, p 106).

What are the reasons the autobiographical authors with Autism give for their above average reluctance to lie? It seems this is so, because of the very intense emotions they experience, when they actually lie. Jeanette Purkis describes it as a very physical or bodily emotion, 'I wanted with every inch of my being to tell the truth' (Purkis 2006, p. 168). Temple Grandin describes emotions of intense fear: 'I become extremely anxious when I have to tell a little white lie' and 'Lying is very anxiety-provoking because it requires rapid interpretations of subtle social cues to determine whether the other person is really being deceived' (Grandin 2006, p. 156). Jen Birch also uses bodily terms in the description of her emotion: 'I found such lies very painful and unpalatable' and 'I still feel 'yucky' about the few times when I was maneuvered into saying that I was something that I am not' (Birch (2003 p. 121). This last author clearly articulates her feeling of moral repugnance against lying, which is an instance of 'moral intuition' with regard to lying (Hare 1981, p. 58).

Some persons with Autism learn to categorize situations and statements and by that way understand how to manage in an ordinary (not always truthful) environment. This categorization will give a lawful character to deception; it can be predicted when lying and deception may be allowed and when it is ruled out. Temple Grandin's classification of wrongdoing, her distinction between 'really bad', 'sins of the system', and 'illegal but not bad' serves this purpose. She writes: 
"I constructed a decision-making program for whether rules could be broken by classifying wrongdoing into three categories: "really bad", "sins of the system", and "illegal but not bad". Rules classified as really bad must never be broken. Stealing, destroying property, and injuring other people are in this category, and they were easy to understand. The "illegal but not bad" rules can often be broken with little consequence. Examples would be slight speeding on the freeway and illegal parking. The "sins of the system" category covers rules that have very stiff penalties for seemingly illogical reasons". (Grandin 2006, p. 108)

This approach can be seen as a cognitive way to overcoming the 'inability' to lie and deceive and hence make everyday life smoother. However, by no means do we suggest that this approach can be generalized to other persons with Autism. It should be regarded as just an individual answer to the problems with following rules an individual person with Autism experiences.

\section{Persons with Autism, empathy and morality}

It has already been stated that persons with Autism are deficient in the ability to empathize with others. Simply stating that persons with Autism lack empathy, however, is going too far. We have to distinguish between cognitive empathy and emotional empathy. The former is 'the ability to understand and predict the behavior of others in terms of attributed mental states, particularly epistemic mental states such as believing, knowing, pretending, and guessing'. The latter is 'an emotional response in an individual that stems from and parallels the 
emotional state of another individual' (Smith 2009, p. 490). According to David Shoemaker, persons with Autism are capable of emotional (or identifying) empathy and therefore they are eligible for membership of the moral community. It is this aspect of empathy, and not the cognitive aspect, that is 'essential to interpersonal engagement and membership in the moral community’ (Shoemaker 2007, p. 97). Psychopaths ${ }^{7}$, who have cognitive empathy but lack emotional empathy are for this reason excluded from the moral community. To morally address psychopaths is pointless. However, morally addressing persons with Autism does make sense. They 'share the cares of the object of empathy (at least with respect to the events giving rise to the empathy)'. They are 'emotionally vulnerable with respect to the fortunes of the items the person with whom they empathize cares about and vulnerable in a roughly similar way to the person with whom they empathize' (Shoemaker 2007, p. 98).

The ethics of care allocates substantial importance to emotions in our moral thinking. It is however important not to have a too narrow view of emotions. Recently the cognitive or rational significance of emotions has been emphasized. Emotions can have evaluative propositional content (Greenspan 2004, p. 125) and can be seen as judgments of value and importance (Nussbaum 2004, p. 183).

The deficit in cognitive empathy of persons with Autism is a problem when persons with Autism should want to engage in an ethics of care perspective. But they may be able to make up for that deficiency in a more cognitive or a more rational way. There appears to be no problem for persons with Autism when they should want to engage in a Kantian perspective. Kant's rigorist convictions on the subject of lying, e.g., are strikingly mirroring the attitude of persons with Autism towards lying. However, this is only a superficial resemblance and more needs to be said about the differences between Kantian thinking with regard to truth telling and autistic thinking. To this we turn now.

\footnotetext{
${ }^{7}$ Psychopaths can also be autistic. Michael Fitzgerald (2010) wrote about a subcategory of Asperger's syndrome which he calls Criminal Autistic Psychopaths.
} 


\section{A Kantian perspective on lying and being truthful}

Immanuel $\mathrm{Kant}^{8}$ had strong convictions about truthfulness. From his 'Groundwork of the Metaphysics of Morals' follows that, on the basis of the categorical imperative ${ }^{9}$, it is absolutely impermissible to lie, even for the sake of the good. The source of morality is rationality, and so the first and third formulations of the categorical imperative test the consistency of actions with their generalization. If everybody would lie all the time, it would be impossible to understand each other at all. So lying is an immoral behavior, independent of the consequences in a particular situation. ${ }^{10}$ If you undermine this, so Kant argued, then you undermine morality (Guseinov 2010, p.33).

In our society, the morals in practice seem to be less demanding than the Kantian 'moral law'. Therefore we can see a tension between the moral practices of everyday life and the moral principles about deception (Nyberg 1993, p. 65). ${ }^{11}$ On the other hand, the breakdown of trust is fairly easily reached in personal relations after telling a lie, at least if it regards something important. It would seem that a requirement of truthfulness about important matters is necessary to lay the foundation of our personal relation to other people.

\footnotetext{
${ }^{8}$ It has been suggested that Immanuel Kant himself had Asperger's syndrome (Fitzgerald, 2005, p. 119-125).

9 "The categorical imperative is thus only a single one, and specifically this: Act only in accordance with that maxim through which you can at the same time will that it become a universal law" (Kant 2002, p.37/ Ak 4, p. 421).

${ }^{10}$ Kant exemplifies this with promises which are never intended to be kept. Used generally, this would make the very idea of promises obsolete. The same applies to lies.

"For the universality of a law that anyone who believes himself to be in distress could promise whatever occurred to him with the intention of not keeping it would make impossible the promise, and the end one might have in making it, since no one would believe that anything has been promised him, but rather would laugh about any such utterance as vain pretense." (Kant 2002, p.39/ Ak 4, p. 422)

${ }^{11}$ In his often discussed essay "On a supposed right to lie from philanthropy" from 1797, Kant takes position to a more relativized standpoint, rejecting it with regard to legal rather than to moral laws, but rejecting it still rigorously; independently from the consequences. His rejection, however, only regards lying if one cannot evade a statement. Insofar Kant does not urge us to ruthless or impolite truthtelling. Modern Kantians try to explain how a less rigorist and counter-intuitive interpretation of a Kantian ethics could be justified. (Korsgaard 1996, Shapiro 2006) We cling here to a more traditional interpretation of Kant, as this is the one that is addressed in the comparison between autistic and Kantian judgments on lies and deceptions.
} 
These empirical questions do not address Kant's more fundamental point of moral foundation, however. From a Kantian perspective we have a duty to be absolutely truthful in our personal and in our moral relations. A moral saint would be unable to lie, because however well-meant or prudential a lie can be, it is simply immoral, irrational and wrong. Are persons with Autism very close to moral saints then?

Autistic truth telling could be easily confused with Kantian absolutism. The source of Kantian truth telling, however, is totally opposite to the source of truth telling of persons with Autism. Kant, with all his preference of rationality and systematics, has another idea of truth and lying. For him in his Groundwork, lying is deliberately stating something that is not the case. The inconsistency that a lie produces with regard to communication, if used systematically, is rather what makes it immoral. This is a purely cognitive, theoretical insight, not touched by practical or emotional reinforcements. ${ }^{12}$ The persons with Autism report strong emotional resistances against lying. For Kant this would be a reason to be careful about the impulse. It is not better to act morally with the support of an inner drive. On the contrary, the right impulse would be to act rightly for the moral law's sake, emotionless. ${ }^{13}$ Not because one wants to do something good, and because one feels bad if one does not do it.

The persons with Autism, however, seem to be very sensitive for inconsistencies in the system, though in an intuitive way. Every single particular truth seems to be equally important. Persons with Autism cannot disregard a particular truth for the 'truth' of the whole, like neurotypicals, contrary to Kant, sometimes do. Persons with Autism do not need the

\footnotetext{
${ }^{12}$ It does matter, however, which understanding of truth-telling, lying and deception is addressed. If one understands lying as interfering with another person's autonomy (Korsgaard 1996, 347), or as the failure of symmetric creation of a common moral horizon (Shapiro 2006, 50-51), truth-telling is no longer the report of one's own perspective on facts, but a complex interpersonal interaction. This is however obviously not the way persons with Autism use the term "lying" and "truth-telling" in self-reports, but more directly as intentional falsehood telling.

13 "To be beneficent where one can is a duty, and there are souls so sympathetically attuned (...). But I assert that in such a case the action (...) has no true moral worth (...); for the maxim lacks moral contents, namely the action not from inclination but from duty. " (Kant 2002, p.14/ Ak 4, p. 398).
} 
categorical imperative as a law; they live $i^{14}$. From a Kantian perspective, this is not the moral ideal. It would be, if they had chosen this orientation themselves, without emotions, even more praiseworthy if done against emotions. Nevertheless, if a person with Autism should receive moral training from a Kantian, it would be a cognitive training. What he or she had to learn is replacing the intuitive background with a purely cognitive one - not feeling bad about lying and about the reactions of others who demand more context-sensitivity and politeness, but defending his or her position in a rational way, and demanding the same uncompromising truthfulness of all others.

\section{An ethics of care perspective on lying and being truthful}

In reaction to Kantian ways of thinking, the ethics of care criticizes moral thinking in terms of rules, laws and duties, and introduces the importance of good caring relationships between human beings as an essential feature of morality. Care as an orientation or as a perspective is directed at living good in concrete relationships with others, responding empathically to their needs and building up a joint life (Verkerk 2001, p. 290). Persons with Autism are by nature not very competent in building relationships. The care ethicist Michael Slote bases caring in empathy (Slote 2007, p. 10). Because persons with Autism are weak empathizers and weak relationship builders, the ethics of care perspective is difficult to access for persons with Autism.

This is problematic for the usability of an ethics of care perspective. Persons with Autism are generally moral agents belonging to the moral community and they are able to understand,

\footnotetext{
${ }^{14}$ This does not imply persons with Autism would have no freedom of choice. They have, and they can lie, if necessary. They have not chosen their make-up and their inclination towards the truth, however. This predisposition does not make them more similar to saints in Kant's sense than neurotypicals, though one could easily suspect that.
} 
apply, and act on moral reasons (Shoemaker 2007, p. 95). Yet, by emphasizing empathy and relationships, the ethics of care perspective appears to exclude a substantial subset of moral agents from making use of this particular perspective. The ethics of care perspective will make little sense to moral agents with Autism. The difficulties become apparent in the ability or disability to tell everyday lies and to tell justifiable lies.

It is clear that from a prudential point of view it is not good to have an autistic 'inability' to lie. Small everyday lies seem to be a necessary means to reach the goal of a healthy lifetime of relationships with others. Therefore, the autistic predisposition to be truthful or the autistic 'inability' to lie is an obstacle for living the good life, at least for them. On the other hand, there is also a vital question about the value of truth and truthfulness to sustaining relationships. However, for the sake of brevity we will not deepen this question here but we will simply state the observation that in healthy relationships there needs to be a healthy balance between being truthful and being deceptive.

The ethics of care perspective seems to suggest that the autistic predisposition to be truthful or the autistic 'inability' to lie can also be an obstacle for living the good life for others. The radical 'inability' to lie and deceive can be an obstacle for acting morally. That can be illustrated by the Kantian example of a murderer who comes to your home to ask you whether or not his intended victim hides in your house might clarify this. You need 'Theory of Mind' to be able to guess the intention behind this question. It would be 'careless', in a literal sense, to speak the truth to this person. So it would seem that the stronger emotions of persons with Autism against lying in such extreme, but nevertheless realistically imaginable, situations are more a burden than an asset.

Starting from an ethics of care perspective, a neurotypical moral agent can context- and relationship-sensitively, come to a conclusion about when it is wrong, but also when it is good to lie. However, a moral agent with Autism would have a hard time assessing 
such a moral situation when he or she starts from an ethics of care perspective, given his or her deficit in cognitive empathy and his or her lack of practical knowledge in the dynamics of relationships. Unless ethics of care theorists do not recognize persons with Autism to be moral agents, because of this cognitive empathy deficit, they will have to take into account in their theorizing the natural limitations of autistic moral agents in order not to be discriminating.

\section{Why persons with Autism should learn the social skill of (some) deception}

When we look at the relationships between neurotypical and persons with Autism we see that it is important that neurotypical persons become aware of the fact that persons with Autism tend to cling to truthfulness. This means that neurotypical persons cannot expect them to lie, e.g. in instances where neurotypicals do not want their own feelings to be hurt by 'rude' remarks. What they should realize is that such remarks of persons with Autism are not made with the intention to hurt but are just attempts to communicate truthfully. Realizing this difference would dissolve some problems neurotypical persons have with the honesty of persons with Autism. A reminder of Kantian ethics might help neurotypicals to see the morally good sides in the uncompromising truthfulness of persons with Autism. In order to promote positive relationships between neurotypical and persons with Autism, neurotypical persons should be tolerant towards the natural and particular truthfulness of persons with Autism.

We acknowledge that there is a problem if one does not immediately recognize a person as having Autism; a neurotypical can be rather upset by a 'rude' remark from such a person, which would have been excused if the information on Autism had been available. Should persons with Autism inform about their condition to avoid such problems? This question, although interesting, is outside the scope of this paper. 
On the other hand, because persons with Autism are regarded as moral agents, they appear to have a moral responsibility, just as neurotypical persons, to sometimes refrain from making truthful statements or to sometimes even make untruthful statements. However, they can only be held responsible to the extent of their capabilities with regard to truth telling or telling lies. We should be careful not to confuse an autistic disability with a moral deficiency.

For the moral development of neurotypical persons and persons with Autism alike, it does not seem useful to prefer the Kantian project. One of the most important tasks is to develop context-sensitivity and responsibility with regard to uttering true statements. As Temple Grandin has shown impressively with her own rule system, it is perfectly possible to use individual strengths of creating rules and patterns for this purpose.

Can we find a common ground for neurotypicals, who are often too good at lying, and persons with Autism, who have great difficulties in telling even a small lie? We think that persons with Autism need to be trained in lying and deception in order to live healthier lives in relationship with others, in the same way that neurotypical children need to learn not to lie too much. The 'training in lying and deception' must be focused on contextsensitivity, that is, on a cognitive explanation under which circumstances it is advisable to lie. This could also empower the person with Autism for situations where lying is morally necessary e.g. to protect the lives, health and well-being of innocent others. The rules that Temple Grandin has created for herself in order to distinguish situations which account for an exception of rules and principles, can serve as an example. However, whether such training will increase health and well-being for the persons with Autism themselves is a matter of empirical research. Training in deception that leads to a decrease in health and well-being of the participants with Autism is already for this reason immoral. So, after an examination of classical Kantianism and care ethics we come to the following conclusion: Unless such an 
education undermines the health and well-being of persons with Autism, it is morally good to teach children and adolescents with Autism the social skill of lying empathically.

\section{References}

Barnbaum, D.R. 2008. The ethics of Autism; among them, but not of them. Bloomington: Indiana University Press.

Baron-Cohen, S. 1999. 'Can Studies of Autism Teach us About Consciousness of the Physical and the Mental?' Philosophical Explorations 2(3): 175-188.

Baron-Cohen, S. 2008. Autism, hypersystemizing, and truth, The Quarterly Journal Of Experimental Psychology 61(1): 64-75.

Birch, J. 2003. Congratulations! It's Asperger Syndrome. Philadelphia: Jessica Kingsley Publishers.

DePaulo, B. M., D.A. Kashy, S.E. Kirkendol, M.M. Wyer, and J.A. Epstein. 1996. Lying in everyday life. Journal of Personality and Social Psychology 70: 979-995.

Fallis, D. 2010. Lying and deception. Philosophers' imprint 10(11): 1-22.

Fitzgerald, M. 2005. The Genesis Of Artistic Creativity: Asperger's Syndrome And The Arts. London: Jessica Kingsley Publishers. 
Fitzgerald, M. 2010. Young, Violent, and Dangerous to Know. Hauppauge, New York: Nova Science Publishers.

Fleisher, M. 2003. Making Sense of the Unfeasible : My Life Journey with Asperger Syndrome. Philadelphia: Jessica Kingsley Publishers.

Gavrilets, S., and A. Vose. 2006. The dynamics of Machiavellian intelligence. Proceedings of the National Academy of Sciences (PNAS) 103(45): 16823-16828.

Grandin, T. 2006. Thinking in Pictures: My Life with Autism (Expanded Edition).

Westminster, Maryland: Knopf Publishing Group.

Greenspan, P. 2004. Emotions, rationality and mind/body. In: Thinking about feeling; contemporary philosophers on emotions, Ed. by R.C. Solomon. Oxford: Oxford University Press.

Guseinov, A.A. 2010. What Kant said, or why is it impermissible to lie for the good? Russian Studies in Philosophy 48(3): 26-47.

Kant, I. 2002. Groundwork for the Metaphysics of Morals. New Haven, Connecticut: Yale University Press.

Kant, I. 1997. On a supposed right to lie from philanthropy. In: Cambridge edition of the works of Immanul Kant in translation. New York: Cambridge University Press. 
Kennett, J. 2002. Autism, empathy and moral agency. The Philosophical Quarterly 52(208): 340-357.

Kleinman, J., P.L. Marciano, and R.L. Ault. 2001. Advanced theory of mind in highfunctioning adults with Autism. Journal of Autism and Developmental Disorders 31: 29-36.

Korsgaard, C. 1996. Creating the kingdom of ends. New York: Cambridge University Press.

Kuhn, T.S. 1977. The essential tension; selected studies in scientific tradition and change. Chicago: The University of Chicago Press.

Lawson, W. 2009. Single Attention and Associated Cognition in Autism (SAACA). PhD thesis, Deakin University.

Mór, C. 2007. Blessing and a Curse: Autism and Me.

London: Jessica Kingsley Publishers.

Nordenfelt, L. 1987. On the nature of health. Dordrecht: Reidel.

Nussbaum, M. 2004. Emotions as Judgments of value and importance. In: Thinking about feeling; contemporary philosophers on emotions, Ed. by R.C. Solomon. Oxford: Oxford University Press. 
Nyberg, D. 1993. The varnished truth: truth telling and deceiving in ordinary life. Chicago: The University of Chicago Press.

Purkis, J. 2006. Finding a Different Kind of Normal: Misadventures with Asperger Syndrome. London: Jessica Kingsley Publishers.

Schneider, E. W. 1999. Discovering My Autism : Apologia Pro Vita Sua (With Apologies to Cardinal Newman). London: Jessica Kingsley Publishers.

Shoemaker, D. 2007. Moral Address, Moral Responsibility, and the Boundaries of the Moral Community. Ethics 118: 70-108.

Shapiro, T. 2006. Kantian rigorism and mitigating circumstance. Ethics 117, 32-57.

Slote, M. 2007. The ethics of care and empathy. New York/Routledge.

Smith, A. 2006. Cognitive empathy and emotional empathy in human behavior and evolution. The Psychological Record 2006(56): 3-21.

Verkerk, M. 2001. The care perspective and autonomy. Medicine, Health Care and Philosophy 4: 289-294.

Wing, L. 1997. The autistic spectrum. The Lancet, 350(9093): 1761-1766. 
